\title{
CELIAC DISEASE AND NEW ATTEMPTS TO DEVELOP GLUTEN-FREE MEAT PRODUCT FORMULATIONS
}

\section{Burcu Öztürk Kerimoğlu ${ }^{\mathbb{D}}$, Meltem Serdaroğlu (iD}

Cite this article as:

Öztürk Kerimoğlu, B., Serdaroğlu, M. (2019). Celiac disease and new attempts to develop gluten-free meat product formulations. Food and Health, 5(4), 253-264. https://doi.org/10.3153/FH19026

Ege University, Engineering Faculty, Food Engineering Department, 35100, Bornova, Izmir, Turkey

ORCID IDs of the authors:

B.Ö.K. 0000-0001-9777-8510

M.S. 0000-0002-3802-3203

Submitted: 11.10 .2018

Revision requested: 14.11 .2018

Last revision received: 16.11 .2018

Accepted: 07.01.2019

Published online: 04.09.2019

Correspondence:

Burcu ÖZTÜRK KERIMOĞLU

E-mail: burcu.ozturk@ege.edu.tr

\begin{abstract}
Celiac disease (CD) is one of the most common diseases related to nutrition affecting consumers all over the world. There has been a steady increment in the production of ready-to-eat meat products with rapid changes in dietary habits, urbanization, and globalization. Despite this increase in manufacturing of ready-to-eat meat products, there is still a market demand present for gluten-free meat products. Since the only treatment for $\mathrm{CD}$ is a lifelong gluten-free diet, an undeniable need is present for meeting the nutritive demands of CD sufferers by improving the range of gluten-free products with both high nutritive and technological quality. The present paper overall covers the $\mathrm{CD}$ and its impacts in connection with the development strategies for gluten-free meat product formulations.
\end{abstract}

Keywords: Gluten, Gluten-free diet, Gluten-free meat products, Celiac disease

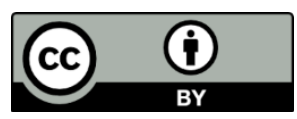

CCopyright 2019 by ScientificWebJournals Available online at 


\section{Introduction}

In the last decades, there has been a rising demand for ready-to-eat food products depending on the progress of production technologies, globalization, and the modernization of everyday life. Coated meat products are one of the ready-to-eat foods that are very popular and widely consumed in mass consumption areas as well as at home. These kinds of products, commonly named as "nuggets", present advantages in terms of short preparation time, high sensory quality and low costs (Dogan et al., 2005, de Carvalho et al., 2018). The industrial production of nuggets mainly consists of portioning the dough that contains meat, fat, and salt; pre-dusting the surface of each portion with a dry flour; battering with a semi-liquid mixture of flours, starches, eggs, water, spices and other ingredients; coating the outer surface with flours and/or breadcrumbs and finally deep-fat frying to stabilize the coating material (Akgün, 2006, Gökçe et al., 2016, de Carvalho et al., 2018). Battering and coating materials provide many desired characteristics to the product such as appealing appearance, attractive color, crispness, adhesion and flavor (Jackson, 2016).

One of the most common battering and/or coating ingredients in nugget formulations is wheat flour which contains approximately 60\% gluten (Jackson et al., 2006). Gluten is the main structural protein in wheat flour, which's main protein fractions, glutenin and gliadin, are highly responsible for the technological and sensory characteristics of many baked products (Gallagher et al., 2004, Jnawali et al., 2016). Regarding coated meat products, gluten is mentioned to play a key role in holding the gases that are formed by the impact of leavening agents and thereby creating a porous structure that enhance the texture. This underlines the fact that increased concentrations of gluten in the coating material could improve the crispness and the color of the deep-fat fried product (Akgün, 2006). Due to its high fat and water binding capacity, gluten also has a considerable application potential in the formulation of different meat, poultry, and fish products, besides it has a strong ability to bind meat pieces in restructured meat products leading enhancement in sliceability and decrement in cook losses (Taşbaş et al., 2016).

Despite all these highlighted benefits, consumption of gluten-containing food products might cause serious health issues for some consumers. Celiac disease (CD) is one of the most remarkable gluten-related disorders that affects approximately $1 \%$ of the world population (Cui et al., 2017, Gobbetti et al., 2018). Since the only treatment for CD is a lifelong gluten-free diet (Gobbetti et al., 2018), it is a notable issue to enhance the options for gluten-free food products that could meet the demands such as sensory and nutritional quality, as well as product costs.

Although a plenty of gluten-free food products, such as bread, pasta, cookies, and cakes are today available in the market, there is still a need for gluten-free meat products for consumption of CD sufferers. Within this review, it was objected to emphasize the general impacts of $\mathrm{CD}$ and its relation to the consumption of coated meat products in terms of new strategies to design novel gluten-free formulations.

\section{A Brief Look at Celiac Disease and Its Impacts}

Although CD is the most common gluten-related disorder, in fact, there are many different diseases caused by gluten consumption including non-celiac gluten sensitivity, dermatitis herpetiformis (Duhring disease), wheat allergy, gluten ataxia, and irritable bowel syndrome (Sapone et al., 2012, Cui et al., 2017, Gobbetti et al., 2018). However, within this review, we will mostly focus on the influences of $\mathrm{CD}$ and its connection with the diet, in particular with coated meat products. CD (gluten-sensitive enteropathy or coeliac sprue) is a permanent food intolerance induced by gluten present in some cereals like wheat, barley and rye (Gallagher et al., 2004, Demir and K1lınç, 2016, Foschia et al., 2016, Cui et al., 2017). Accounts of CD date back to the first century A.D. in the medical books of Aretaeus from Cappadocia (Farrell and Kelly, 2002). After the Neolithic revolution that began in the area surrounding modern Turkey, Iraq, and Iran called "Fertile Crescent", agricultural practices, the major living and thereby dietary changes led to the appearance of "new" diseases such as CD (Rostami et al., 2004). Today it is one of the most common lifelong disorders based on nutrition affecting mankind all over the world (Lionetti et al., 2015, Demir and K1lıç, 2016).

Gluten proteins are storage proteins that occur exclusively in the starchy endosperm of the grains and make up approximately $70-80 \%$ of total grain proteins (Scherf 
et al., 2016). Gluten proteins have two major groups: the ethanol-soluble fraction termed prolamins and the polymeric glutenins. When reacted with alcohol, the toxic fractions of prolamins, which are called "gliadins" from wheat, "secalins" from rye and "hordeins" from barley are formed (Ciclitira et al., 2005, Niewinski, 2008). These residues are toxic to the small intestinal mucosa of patients with $\mathrm{CD}$ and cannot be completely digested by peptidases from the stomach, pancreas, and intestinal brush borders (Ciclitira et al., 2005, Cui et al., 2017). CD predominantly affects the mucosa of the upper small intestine and is characterized by "villous atrophy" that leads a broad flat villi which is associated with maldigestion and malabsorption of nutrients, vitamins, and minerals (Niewinski, 2008, Scherf et al., 2016). CD commonly appears in early childhood, with sore symptoms including chronic diarrhea and failure to thrive, or the symptoms can also develop later in life (Foschia et al., 2016). The disease can occur at any age with females being more commonly affected than males with a suggested ratio of around 2:1 (Scherf et al., 2016). The symptoms mainly include abdominal pain, chronic or intermittent diarrhea, vomiting, chronic constipation, abdominal distention, weight loss, weakness, severe malnutrition and many other extra-intestinal associations that could cause further complications (Niewinski, 2008, Scherf et al., 2016, Cui et al., 2017). Moreover, $\mathrm{CD}$ also places patients at greater risk for certain cancers (Cui et al., 2017), mycotoxins and major depressive disorder (Gobbetti et al., 2018).

$\mathrm{CD}$ is one of the most common genetically based disease, about $97 \%$ of individuals with $C D$ have genetic markers on chromosome $6 \mathrm{p} 21$, called class-II human leukocyte antigen (HLA), specifically HLA-DQ2 and HLA-DQ8 (Niewinski, 2008). Although genetic factors play an important role in the development of CD, environmental factors are also effective. Since the disease would not be seen as far as wheat and other glutencontaining cereals are included in the diet, the incidence of CD has increased in societies where wheat has an important place in nutrition, or in some ethnic groups that have changed their dietary habits (Demirçeken, 2011). According to Lionetti et al. (2015), the widespread diffusion of CD is not surprising given that its causal factors show a worldwide distribution. In addition, the common use of refined grains and leavening by chemical and baker's yeast agents are some of the examples of the most recent trend (Gobbetti et al., 2018).

In some recent studies, the worldwide prevalence of CD has been reported as between 0.3-2\% (Lionetti et al., 2015, Cui et al., 2017), briefly, the overall prevalence has been stated as 1\% on average (Lionetti et al., 2015, Jackson, 2016). Although CD was previously considered as a typical disease of European origin, later it was theorized that the pattern of agriculture spreading could explain the higher CD incidence in some western countries like Ireland (Rostami et al., 2004). Nevertheless, the highest reported prevalence is in western Europe and in places where Europeans emigrated like North America and Australia. However, it is also found in northwest India and may be underdiagnosed in South America, North Africa and Asia (Farrell and Kelly, 2002, Lionetti et al., 2015). These regional differences may arise from variation in HLA or other genetic factors, dietary habits, infant feeding practices, gastrointestinal infections, socioeconomic status, hygiene, or other unknown effects (Unalp-Arida et al., 2017). Also, it should be noted that in Western countries the overall incidence of the disease is on the rise, probably due to the environmental components (Lionetti et al., 2015) and as reported by Cui et al. (2017), the increasing rate doubles every 20 years.

The prevalence of $\mathrm{CD}$ is commonly explained by the "iceberg model" (Gallagher et al., 2004), which is presented in Figure 1. According to this model, cases which have been properly diagnosed make up the visible section (S1). The CD sufferers who follow a gluten-free diet and show a normal mucosa represent the lower part of this section. Under the waterline (finish line of S1), there begins the silent section (S2), which is referred to undiagnosed patients that have no symptoms or have some symptoms not related to $\mathrm{CD}$. The bottom section of the iceberg (S3) indicates a small group of person with a latent $C D$ that shows a normal mucosa at present but carry the potential to develop $\mathrm{CD}$ in the future (Feighery, 1999, Gallagher et al., 2004). The model clearly indicates that the actual prevalence of CD could be much higher than is reported due to the big invisible areas. Kerpes et al. (2017) also reported that the validity of the prevalence value of CD is unclear because of silent forms and low clinical rates of detection. 


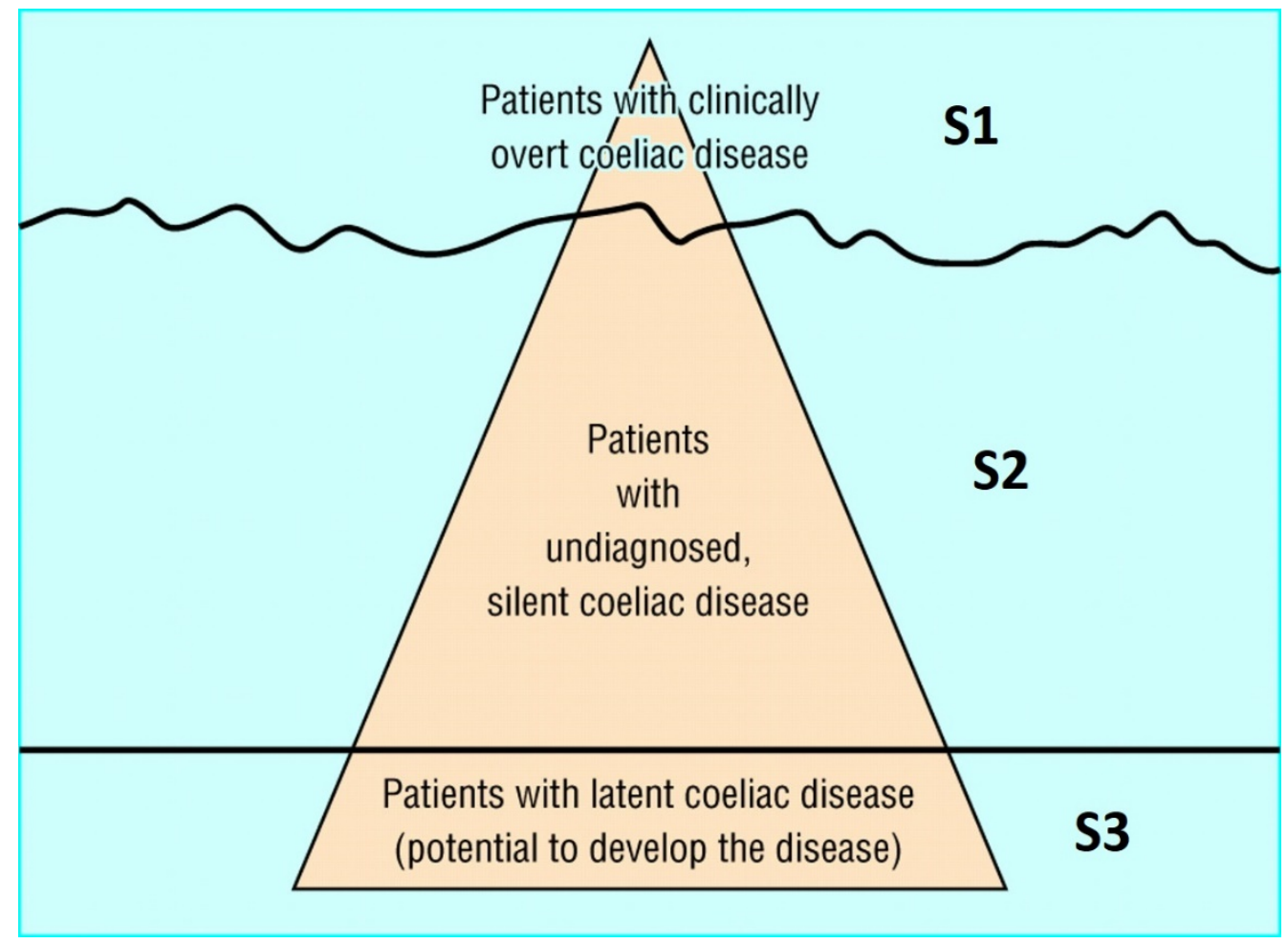

Figure 1. The iceberg model of CD (Feighery, 1999).

\section{Gluten-Free Diet: Challenges and Needs}

The only treatment of CD is to follow a strict and permanent lifelong gluten-free diet, which results in complete remission (Feighery, 1999, Jnawali et al., 2016). The treatment of CD with a gluten-free diet has positive effects on the mucosal histology as it will normalize it and the clinical symptoms will ease (Foschia et al., 2016). Following this diet may seem really easy at the first look, however treating the disease in a developing country can be extremely difficult due to the challenges in its institution and maintenance of adherence (Lionetti et al., 2015). Jnawali et al. (2016) notified that a glutenfree diet not only involves eliminating gluten-containing cereals and their products but also requires constant vigilance and a complete change in lifestyle. Even though most patients self-report strict dietary gluten adherence, a significant number have persistent mucosal damage 2 years after they started a gluten-free diet (Rubio-Tapia et al., 2010). Silvester et al. (2016) assessed the relationship between self-reported adherence to this diet and found out that individuals who believe they are following a gluten-free diet are not able to correctly identify foods that are gluten-free, which suggests ongoing gluten consumption may be occurring. Gobbetti et al. (2018) reported that gluten is safe avoidance of its main sources like wheat and barley, but especially when present as minor ingredients like sausages, instant soups, and confectioneries, it becomes very difficult. Thus novel approaches for definition and categorization of gluten-free food sources and products are needed. As mentioned by Foschia et al. (2016), in order to avoid any type of contamination, gluten-containing ingredients have to be located and manipulated in areas strictly separated from the gluten-free ones.

Lionetti et al. (2015) emphasized that today there is neither an organized sector nor industry for gluten-free food products in developing countries and these products are not readily available. Therefore, it is a notable point to increase the awareness of the disease in both society and governments by improving legislation strategies for gluten labeling, educational applications, and periodical free screen tests. The U.S. Food and Drug Administration (FDA) issued a final rule in 2013 defining the term "gluten-free" for voluntary use in the labeling 
of foods for the benefit both people with CD and the food industry. This rule defines gluten-free as meaning that the food is either inherently gluten-free or does not contain an ingredient that is: (1) a gluten-containing grain (e.g. spelt wheat), (2) derived from a gluten-containing grain that has not been processed to remove gluten (e.g. wheat flour), or (3) derived from a gluten-containing grain that has been processed to remove gluten (e.g. wheat starch), if the use of that ingredient results in the presence of $20 \mathrm{ppm}$ or more gluten in food. Also, any unavoidable presence of gluten in the food must be less than 20 ppm (U.S. Food and Drug Administration, 2018).

Today the consumers are highly aware of nutrition-related diseases and would like to improve physical and mental well-being besides just satisfying hunger (Jnawali et al., 2016). Although CD sufferers have to follow a strict gluten-free diet, also some consumers without CD prefer to take a gluten-free diet due to some health issues, weight management and/or minimizing future risk of gastrointestinal diseases (Gobbetti et al., 2018), also due to the cultural, ecological, civic, historical or ethnical interest of quality (Foschia et al., 2016). In a population-based regional study, it was reported that $0.7 \%$ of participants had CD, while $1.1 \%$ of them avoid gluten without CD (Unalp-Arida et al., 2017). From 2013 to 2015, the gluten-free industry enjoyed a growth of $136 \%$, leaving behind the awareness of the disease (Reilly, 2016). For this reason, the number of consumers seeking for gluten-free product options is remarkable since both of the groups are in need of that kind of diet type. Therefore, it becomes more of an issue to increase the high-quality gluten-free product range and to maximize the options. In a recent review of Jnawali et al. (2016), some specific considerations in the development of gluten-free products have been well-described that includes avoidance of gluten-containing sources (as the challenges are underlined above), ensuring sensory characteristics and nutritional value of the products, meeting the recommended dietary allowances and product costs.

\section{Novel Approaches for Designing Gluten-Free Meat Product Formulations}

Consumers with CD have the opportunity to eat certain types of gluten-free products that are categorized as naturally occurring gluten-free foods (fruits, vegetables, eggs, unprocessed meat, poultry, and fish) and glutenfree substitute foods (bread, pasta, cereals, crackers and snack foods) in which wheat flour is replaced by a gluten-free ingredient (Taşbaş et al., 2016, Cui et al., 2017). In literature, there exists a plenty of studies regarding gluten-free production and related quality parameters of bakery food products like bread (Lazaridou et al., 2007, de la Barca et al., 2010, Hager and Arendt, 2013, Martínez and Gómez, 2017, Rinaldi et al., 2017), pasta (Giuberti et al., 2015, Sanguinetti et al., 2015, Larrosa et al., 2016), cake (Levent and Bilgiçli, 2011, Preichardt et al., 2011, Talens et al., 2017), cookies (Rai et al., 2014, Brito et al., 2015, Molinari et al., 2018), crackers (Radočaj et al., 2014), and also some other foods like tarhana (Yalçin et al., 2008, Bilgiçli, 2009), snacks (Kahlon et al., 2016) and beer (Kerpes et al., 2017). On the other hand, only a limited research data is available on developing gluten-free meat product formulations. Taşbaş et al. (2016) reported that although unprocessed meats are free of gluten, people with CD need to be aware of meats and poultry with added ingredients that make them into ready-to-cook or processed meat products which may contain gluten. Considering the rising trend in production of all kinds of ready-to-eat meat products; since wheat flour and its derivatives are the most common ingredients used in the formulation of these products, there is an irrefutable demand for formulating that kind of products in gluten-free form.

Wheat flour as a traditional batter ingredient of nuggets contains a considerable amount of proteins that are necessary to form elasto-plastic batter (Taşbaş et al., 2016) and thus improve technological quality. Jnawali et al. (2016) stated that since eliminating wheat from the diet would mean the exclusion of a good protein source and sticking to a high carbohydrate diet, the protein content of the alternate source has to be considered. Since most of the gluten-free products are starch-based and thereby have low nutritional value, it is very important to enrich such products for consumers who are obliged to follow a gluten-free diet (Demir and Kılınç, 2016). Also, gluten-free products are mostly known as lacking mineral or to have less fortification with micronutrients and fibers compared to wheat-containing products (Gobbetti et al., 2018). Vici et al. (2016) reported that a glutenfree diet may lead to possible nutrient deficiencies or nutrient excess (e.g. saturated fats). For these reasons, the 
alternative ingredients for gluten replacement should present the potential to overcome the nutritive deficiencies and simultaneously to increase product yield and quality.

According to Adedeji and Ngadi (2011), incorporation of some alternative flours or hydrocolloids in batter formulations of meat products could improve functionality and quality as well as cost-effectiveness, which points out that it could be possible to develop high-quality meat products by using proper gluten-free ingredients. So far, some functional ingredients in formulation of coated meat products have been used with combination of wheat flour to improve overall quality: Dogan et al. (2005) reported that soy flour was found to be an effective ingredient in improving quality of deep-fat fried chicken nuggets in terms of crispness and color, while both soy and rice flours provided reduced oil absorption. Kilincceker and Hepsag (2011) suggested the utilization of yellow lentil flour and chickpea flour as the batter materials of fish balls that improve the yield and sensory properties. In another study, it was reported that the addition of oat flour in breading mixes of chicken meatballs positively affected sensory properties and yield (Kilincceker 2013). Gökçe et al. (2016) investigated some quality characteristics of deep-fat fried chicken nuggets formulated with wheat, corn, rye and soy flours. They reported that the highest cooking yield was found in corn and wheat flour samples, the use of rye flour significantly increased the penetrometer values, and incorporation of corn flour showed the highest yellowness among samples. Kwaw et al. (2017) evaluated different single and composite flours from wheat, millet, sorghum, and soybean as breading agents in the deep frying of chicken breast. They recorded an increase in fat absorption in the single cereal coated samples compared to the composite flours and found that the samples coated with an equal ratio of soybean and sorghum composite flour had the highest overall acceptability. As is seen, in these studies the incorporation of the ingredients did not directly target to replace wheat or to formulate glutenfree formulations, yet this does not mean that these alternates have not a potential to be used in gluten-free meat products. In addition, so far various sources as gluten replacers have been suggested for general use in the formulation of different food products. Demirçeken (2011) stated that rice and corn are the main sources which do not contain toxic prolamine and can safely be consumed in the diet of celiac patients. Some minor cereals such as teff, millets, and Jungle rice, and some legumes such as chickpea, lentil, and soybeans have been mentioned by Jnawali et al. (2016) and Gobbetti et al. (2018) as gluten alternatives carrying potential nutritive benefits. Besides, in the near past, a comprehensive list was also presented by Niewinski (2008), who stressed some other gluten-free ingredients like buckwheat, oats (uncontaminated), sago and sorghum flour. Quinoa, a type of pseudo-cereal, has been suggested as a good alternative for $\mathrm{CD}$ patients since it contains high biological valued proteins, low-glycemic indexed carbohydrates, fitosteroids, w-3 and w-6 fatty acids, micro-nutritional and bioactive compounds (Demir and Kilınç, 2016). Oat, another functional source that contains proteins, essential amino acids, and various antioxidants, is tolerated by almost all CD sufferers, although oat intolerance has been described (Ciclitira et al., 2005, Smulders et al., 2018). Smulders et al. (2018) reported that the prolamine storage protein called "avenin" in oat does not contain any of the known $\mathrm{CD}$ epitopes from gluten of wheat, barley, and rye, and long-term food studies confirm the safety of oats for CD patients. Some other gluten-free sources that can be used for developing food products for CD sufferers include nuts (e.g. almonds, hazelnuts, walnut), seeds (e.g. flax seeds, chia seeds, pumpkin seeds) and tubers (e.g. arrowroot, tapioca, potato) (Jnawali et al., 2016). As a result, all these ingredients could be counted as potential alternatives for wheat flour and alike materials to be further incorporated into gluten-free meat product formulations. In addition to the replacement of wheat flour and other gluten-containing ingredients by these types of alternatives, Gobbetti et al. (2018) also mentioned some recent approaches in gluten-free diet such as pre-digestion of dietary gluten, treatments of prebiotics that are capable of hydrolyzing gluten, degradation of wheat flour by use of sourdough and production of genetically modified wheat. 
Table 1. The studies on the formulation of gluten-free meat products

\begin{tabular}{|c|c|c|c|}
\hline Product & $\begin{array}{l}\text { Gluten-free } \\
\text { ingredient(s) }\end{array}$ & Highlights & Reference \\
\hline Chicken nugget & Rice flour & $\begin{array}{l}\text { Value was added to the products by utilizing rice flour in } \\
\text { the production of gluten-free products without diminishing } \\
\text { sensory quality as well as lipid reduction through baking. }\end{array}$ & Jackson et al. (2006) \\
\hline Chicken nugget & Sorghum flour & $\begin{array}{l}\text { Use of sorghum flour significantly increased the product } \\
\text { yield, texture and dietary fiber content. It was concluded } \\
\text { that } 5 \% \text { sorghum flour is optimum to prepare gluten-free } \\
\text { nuggets in terms of sensory quality. }\end{array}$ & Devatkal et al. (2011) \\
\hline Kibbeh & Pearl millet flour & $\begin{array}{l}\text { Kibbeh prepared with millet flour presented good oxida- } \\
\text { tion stability. Baked kibbehs with millet flour presented } \\
\text { good acceptability and did not differ from the samples with } \\
\text { wheat flour in terms of appearance, texture, and flavor. }\end{array}$ & Brasil et al. (2015) \\
\hline Chicken nugget & Pecans & $\begin{array}{l}\text { The pecans did not have a significant effect on moisture } \\
\text { content, batter adhesion, or consumer acceptability while } \\
\text { nuggets made with pecans had a higher lipid content. }\end{array}$ & Jackson (2016) \\
\hline Chicken nugget & $\begin{array}{l}\text { Gluten-free } \\
\text { wheat flour in } \\
\text { combination with } \\
\text { cellulose, egg } \\
\text { powder, whey } \\
\text { powder or pectin }\end{array}$ & $\begin{array}{l}\text { The addition of whey powder in the formulation was re- } \\
\text { sulted in decreased oil uptake, increased pick up and water } \\
\text { holding capacity. Lipid oxidation was decreased in the } \\
\text { samples manufactured with wheat flour or whey powder. } \\
\text { The results showed that } 2 \% \text { whey powder can be used in } \\
\text { gluten-free nugget manufacture without posing any quality } \\
\text { problems. }\end{array}$ & Taşbaş et al. (2016) \\
\hline Chicken nugget & $\begin{array}{l}\text { Amaranth flakes } \\
\text { with soy oil, } \\
\text { eggs, oregano or } \\
\text { basil }\end{array}$ & $\begin{array}{l}\text { All of the formulations had similar yields. The samples } \\
\text { with soy oil showed the highest lipid, carbohydrate, and } \\
\text { mineral content and had a better acceptance for all evalu- } \\
\text { ated sensory attributes. }\end{array}$ & de Carvalho et al. (2018) \\
\hline Chicken nugget & $\begin{array}{l}\text { Rice flour (RF), } \\
\text { chickpea flour } \\
(\mathrm{CF}) \text {, oat fiber } \\
\text { (OF) or Jerusa- } \\
\text { lem artichoke } \\
\text { powder (JAP) }\end{array}$ & $\begin{array}{l}\text { Utilization of OF and JAP decreased moisture, RF and OF } \\
\text { increased protein, JAP decreased fat and OF decreased car- } \\
\text { bohydrate content of the samples. Samples with OF and } \\
\text { JAP was effective to provide an equivalent cooking yield } \\
\text { to wheat flour samples. JAP samples had the lowest oil ab- } \\
\text { sorption among treatments. }\end{array}$ & Öztürk et al. (2018) \\
\hline Fish patty & $\begin{array}{l}\text { Rice, corn, ama- } \\
\text { ranth or quinoa } \\
\text { flours }\end{array}$ & $\begin{array}{l}\text { Flours addition affected proximate composition increasing } \\
\text { carbohydrates, total fat and mineral content compared to } \\
\text { control. No differences were found in the aroma of prod- } \\
\text { ucts. Addition of rice flour increased juiciness and tender- } \\
\text { ness whereas taste, overall acceptance and buying intention } \\
\text { were higher in control patty, followed by patties made with } \\
\text { corn flour. }\end{array}$ & Romero et al. (2018) \\
\hline
\end{tabular}


Getting back to the main idea, some key highlights of recent studies on gluten-free meat products are summarized in Table 1. As well as the general potential of the alternative ingredients has been emphasized above, it could be seen that some of these ingredients have been already used in the formulation of different kinds of meat products. In the studies, gluten-free meat products have been formulated with some ingredients such as gluten-free wheat flour itself, rice flour, sorghum flour, pecans, amaranth flakes, chickpea flour, oat fiber, and Jerusalem artichoke powder, as wheat flour replacers. It was recorded that most of these ingredients were able to increase product yield in terms of cook loss and adhesion ratios without negatively affecting sensory quality, to improve nutritional value, and to retard lipid oxidation, meaning that these compounds could present multifunctional benefits on overall quality. Jackson et al. (2006) reported that rice-based products can be used to reduce the fat content of deep-fried, battered chicken because rice flour batter absorbs less oil than wheat flour batter due to chemical differences between proteins and thus prevents products against lipid oxidation. Sorghum flour was mentioned to be a good source of dietary fiber as a non-glutinous flour that could be used in the scope of making gluten-free meat products (Devatkal et al., 2011). Jackson (2016) stressed that pecans can be used as an ingredient in breaded chicken nuggets with its high dietary fiber content, nutritive features, and health benefits. In another study, it was suggested that the combination of gluten-free wheat flour and whey protein can be a suitable alternative to produce good-quality glutenfree coated chicken products (Taşbaş et al. 2016). de Carvalho et al. (2018) stated that amaranth (Amaranthus) grains have emerged as an attractive raw material to replace wheat in the development of products for celiac individuals, with a high content of high biological quality protein, minerals, and vitamins. Öztürk et al. (2018) recommended that especially dietary fiber sources could supply to formulate gluten-free poultry products that have equivalent cooking characteristics to standard gluten-containing products, meanwhile improving health profile. Except for coated meat products, some non-glutinous flours have been also mentioned to improve nutritive, sensory and technological quality of different gluten-free meat products like fish patties (Romero et al., 2018) and kibbeh (Brasil et al., 2015).
Consequently, overall data indicated that the utilization of alternative gluten-free natural sources in the formulation of meat products presents the opportunity to produce high-quality and nutritive products, as well as to decrease product costs.

\section{Conclusion}

$\mathrm{CD}$ is effective on approximately $1 \%$ of the world population and showing a steadily increasing trend. Also, the real prevalence is thought to be much higher due to the silent forms in the iceberg. Today the only available and accepted solution for CD is a strict and permanent gluten-free diet. Besides, it is a fact that not only celiac patients but also those who would like to consume gluten-free products prefer this diet. However, currently, most of the gluten-free products in the market are mentioned to have low nutritional value and overall quality. At the same time, the labeling and classification practices are insufficient as well as some consumers could barely obey the rules of the gluten-free diet. Therefore, it is a fact that there is still a gap between gluten-free products and quality. Secondly, although some bakery foods are already available in the market, there are only a few options present for the gluten-free meat products. Since meat is one of the main sources of proteins and essential nutrients in the diet, the lack of meat and meat products may cause serious deficiencies. Accordingly, the development of novel strategies in meat products for consumers with gluten sensitivity is important to increase the consumption of such products in the diet of these individuals. In particular, increasing the variety of gluten-free ready-to-eat meat products like nuggets, sausages, and meatballs is necessary for especially adolescents and children who mostly prefer to consume that kind of products and whom self-adherence is much lower than adults. In addition, future studies are needed to formulate new gluten-free meat products by using dietary fiber sourced ingredients.

\section{Compliance with Ethical Standard}

Conflict of interests: The authors declare that for this article they have no actual, potential or perceived conflict of interests.

Financial disclosure: This study was supported by The Republic of Turkey, Ministry of Science, Industry, and Technology (Project No: 0764.STZ.2014, SANTEZ Program). 


\section{References}

Adedeji, A.A., Ngadi, M.O. (2011). Microstructural properties of deep-fat fried chicken nuggets coated with different batter formulation. International Journal of Food Properties, 14(1), 68-83.

https://doi.org/10.1080/10942910903131423

Akgün, A.A. (2006). The sensory, physical, chemical, and microbiological characteristics of chicken meatballs coated using different coating formulations. Pamukkale University, Institute of Science, Master Thesis, Denizli, Turkey, 75 p.

Bilgiçli, N. (2009). Enrichment of gluten-free tarhana with buckwheat flour. International Journal of Food Sciences and Nutrition, 60(Suppl 4), 1-8.

https://doi.org/10.1080/09637480802112546

Brasil, T.A., Capitani, C.D., Takeuchi, K.P., Ferreira, T.A.P.C. (2015). Physical, chemical and sensory properties of gluten-free kibbeh formulated with millet flour (Pennisetum glaucum (L.) R. Br.). Food Science and Technology, 35(2), 361-367.

https://doi.org/10.1590/1678-457X.6564

Brito, I.L., de Souza, E.L., Felex, S.S., Madruga, M.S., Yamashita, F., Magnani, M. (2015). Nutritional and sensory characteristics of gluten-free quinoa (Chenopodium quinoa Willd)-based cookies development using an experimental mixture design. Journal of Food Science and Technology, 52(9), 5866-5873.

https://doi.org/10.1007/s13197-014-1659-1

Ciclitira, P.J., Ellis, H.J., Lundin, K.E.A. (2005). Glutenfree diet - what is toxic?. Best Practice and Research Clinical Gastroenterology, 19(3), 359-371.

https://doi.org/10.1016/j.bpg.2005.01.003

Cui, C., Basen, T., Philipp, A.T., Yusin, J., Krishnaswamy, G. (2017). Celiac disease and nonceliac gluten sensitivity. Annals of Allergy, Asthma and Immunology, 118(4), 389-393.

https://doi.org/10.1016/j.anai.2017.01.008

de Carvalho, L.R.S., da Silva, C.H., Giada, M.L.R. (2018). Physical, chemical and sensorial properties of low-fat and gluten-free chicken nuggets. Journal of Culinary Science and Technology, 16(1), 18-29.

https://doi.org/10.1080/15428052.2017.1310071

de la Barca, A.M., Rojas-Martínez, M.E., Islas-Rubio, A.R., Cabrera-Chávez, F. (2010). Gluten-free breads and cookies of raw and popped amaranth flours with attractive technological and nutritional qualities. Plant Foods for $\mathrm{Hu}$ man Nutrition, 65(3), 241-246.

https://doi.org/10.1007/s11130-010-0187-z

Demir, M.K., Kılınç, M. (2016). Quinoa: Nutritional and anti-nutritional characteristics. Journal of Food and Health Science, 2(3), 104-111.

https://doi.org/10.3153/JFHS16011

Demirçeken, F.G. (2011). Gluten enteropatisi (çölyak hastalığı): Klasik bir öykü ve güncel gelişmeler. Güncel Gastroenteroloji, 15(1), 58-72.

Devatkal, S.K., Kadam, D.M., Naik, P.K., Sahoo, J. (2011). Quality characteristics of gluten-free chicken nuggets extended with sorghum flour. Journal of Food Quality, 34(2), 88-92.

https://doi.org/10.1111/j.1745-4557.2010.00367.x

Dogan, S.F., Sahin, S., Sumnu, G. (2005). Effects of soy and rice flour addition on batter rheology and quality of deepfat fried chicken nuggets. Journal of Food Engineering, 71(1), 127-132.

https://doi.org/10.1016/j.jfoodeng.2004.10.028

Farrell, R.J., Kelly, C.P. (2002). Celiac sprue. The New England Journal of Medicine, 346(3), 180-88. https://doi.org/10.1056/NEJMra010852

Feighery, C.F. (1999). Coeliac disease. British Medical Journal, 319(7204), 236-239.

https://doi.org/10.1136/bmj.319.7204.236

Foschia, M., Horstmann, S., Arendt, E.K., Zannini, E. (2016). Nutritional therapy - Facing the gap between coeliac disease and gluten-free food. International Journal of Food Microbiology, 239, 113-124.

https://doi.org/10.1016/j.ijfoodmicro.2016.06.014 
Gallagher, E., Gormley, T.R., Arendt, E.K. (2004). Recent advances in the formulation of gluten-free cereal-based products. Trends in Food Science and Technology, 15(3-4), 143152.

https://doi.org/10.1016/j.tifs.2003.09.012

Giuberti, G., Gallo, A., Cerioli, C., Fortunati, P., Masoero, F. (2015). Cooking quality and starch digestibility of gluten free pasta using new bean flour. Food Chemistry, 175, 43-49.

https://doi.org/10.1016/j.foodchem.2014.11.127

Gobbetti, M., Pontonio, E., Filannino, P., Rizzello, C.G., De Angelis, M., Di Cagno, R. (2018). How to improve the gluten-free diet: The state of the art from a food science perspective. Food Research International, 110, 22-32.

https://doi.org/10.1016/j.foodres.2017.04.010

Gökçe, R., Akgün, A.A., Ergezer, H., Akcan, T. (2016). Effects of different batter formulation on some quality characteristics of deep-fat fried chicken nuggets. Journal of Agricultural Sciences, 22(3), 331-338.

Hager, A.S., Arendt, E.K. (2013). Influence of hydroxypropylmethylcellulose (HPMC), xanthan gum and their combination on loaf specific volume, crumb hardness and crumb grain characteristics of gluten-free breads based on rice, maize, teff and buckwheat. Food Hydrocolloids, 32(1), 195203.

https://doi.org/10.1016/j.foodhyd.2012.12.021

Jackson, A. (2016). Consumer evaluation and shelf-life of gluten-free pecan breaded chicken nuggets. The University of Georgia, Athens, USA, 65 p.

Jackson, V., Schilling, M.W., Coggins, P.C., Martin, J.M. (2006). Utilization of rice starch in the formulation of lowfat, wheat-free chicken nuggets. The Journal of Applied Poultry Research, 15(3), 417-24.

https://doi.org/10.1093/japr/15.3.417

Jnawali, P., Kumar, V., Tanwar, B. (2016). Celiac disease: Overview and considerations for development of gluten-free foods. Food Science and Human Wellness, 5(4), 169-176. https://doi.org/10.1016/j.fshw.2016.09.003
Kahlon, T.S., Avena-Bustillos, R.J., Chiu, M.C.M. (2016). Sensory evaluation of gluten-free quinoa whole grain snacks. Heliyon, 2(12), e00213.

https://doi.org/10.1016/j.heliyon.2016.e00213

Kerpes, R., Fischer, S., Becker, T. (2017). The production of gluten-free beer: Degradation of hordeins during malting and brewing and the application of modern process technology focusing on endogenous malt peptidases. Trends in Food Science and Technology, 67, 129-138.

https://doi.org/10.1016/j.tifs.2017.07.004

Kilincceker, O. (2013). Utilization of oat flour as edible coating material on fried chicken meatballs. Focusing on Modern Food Industry, 2(1), 36-42.

Kilincceker, O., Hepsag, F. (2011). Performance of different coating batters and frying temperatures for fried fish balls. Journal of Animal and Veterinary Advances, 10(17), 22562262.

https://doi.org/10.3923/javaa.2011.2256.2262

Kwaw, E., Sackey, A.S., Apaliya, M.T., Tchabo, W. (2017). Utilization of composite flours as breading agents for deep frying of chicken breast. Journal of Food Measurement and Characterization, 11(3), 1523-1530.

https://doi.org/10.1007/s11694-017-9531-4

Larrosa, V., Lorenzo, G., Zaritzky, N., Califano, A. (2016). Improvement of the texture and quality of cooked gluten-free pasta. LWT - Food Science and Technology, 70, 96-103.

https://doi.org/10.1016/j.lwt.2016.02.039

Lazaridou, A., Duta, D., Papageorgiou, M., Belc, N., Biliaderis, C.G. (2007). Effects of hydrocolloids on dough rheology and bread quality parameters in gluten-free formulations. Journal of Food Engineering, 79(3), 1033-1047. https://doi.org/10.1016/j.jfoodeng.2006.03.032

Levent, H., Bilgiçli, N. (2011). Effect of gluten-free flours on physical properties of cakes. Journal of Food Science and Engineering, 1, 354-360. 
Lionetti, E., Gatti, S., Pulvirenti, A., Catassi, C. (2015). Celiac disease from a global perspective. Best Practice and Research Clinical Gastroenterology, 29, 365-379.

https://doi.org/10.1016/j.bpg.2015.05.004

Martínez, M.M., Gómez, M. (2017). Rheological and microstructural evolution of the most common gluten-free flours and starches during bread fermentation and baking. Journal of Food Engineering, 197, 78-86.

https://doi.org/10.1016/j.jfoodeng.2016.11.008

Molinari, R., Costantini, L., Timperio, A.M., Lelli, V., Bonafaccia, F., Bonafaccia, G., Merendino, N. (2018). Tartary buckwheat malt as ingredient of gluten-free cookies. Journal of Cereal Science, 80, 37-43.

https://doi.org/10.1016/j.jcs.2017.11.011

Niewinski, M.M. (2008). Advances in celiac disease and gluten-free diet. Journal of the American Dietetic Association, 108(4), 661-672.

https://doi.org/10.1016/i.jada.2008.01.011

Öztürk, B., Serdaroğlu, M., Karabıyıkoğlu, M. (2018). Quality attributes of chicken nuggets produced by using different gluten-free ingredients. International Poultry Science Congress WPSA Turkish Branch'2018, 09-12 May 2018, Cappadocia, Turkey, p. 192-196.

Preichardt, L.D., Vendruscolo, C.T., Gularte, M.A., Moreira, A.S. (2011). The role of xanthan gum in the quality of gluten free cakes: Improved bakery products for coeliac patients. International Journal of Food Science and Technology, 46(12), 2591-2597.

https://doi.org/10.1111/j.1365-2621.2011.02788.x

Radočaj, O., Dimić, E., Tsao, R. (2014). Effects of hemp (Cannabis sativa L.) seed oil press-cake and decaffeinated green tea leaves (Camellia sinensis) on functional characteristics of gluten-free crackers. Journal of Food Science, 79(3), C318-C325.

https://doi.org/10.1111/1750-3841.12370

Rai, S., Kaur, A., Singh, B. (2014). Quality characteristics of gluten free cookies prepared from different flour combinations. Journal of Food Science and Technology, 51(4), 785789. https://doi.org/10.1007/s13197-011-0547-1

Reilly, N.R. (2016). The gluten-free diet: recognizing fact, fiction, and fad. The Journal of Pediatrics, 175, 206-210. https://doi.org/10.1016/j.jpeds.2016.04.014

Rinaldi, M., Paciulli, M., Caligiani, A., Scazzina, F., Chiavaro, E. (2017). Sourdough fermentation and chestnut flour in gluten-free bread: A shelf-life evaluation. Food Chemistry, 224, 144-152.

https://doi.org/10.1016/j.foodchem.2016.12.055

Romero, M.C., Fogar, R.A., Rolhaiser, F., Clavero, V.V., Romero, A.M., Judis, M.A. (2018). Development of glutenfree fish (Pseudoplatystoma corruscans) patties by response surface methodology. Journal of Food Science and Technology, 55(5), 1889-1902.

https://doi.org/10.1007/s13197-018-3106-1

Rostami, K., Malekzadeh, R., Shahbazkhani, B., Akbari, M.R., Catassi, C. (2004). Coeliac disease in Middle Eastern countries: a challenge for the evolutionary history of this complex disorder? Digestive and Liver Disease, 36(10), 694697.

https://doi.org/10.1016/j.dld.2004.05.010

Rubio-Tapia, A., Rahim, M.W., See, J.A., Lahr, B.D., Wu, T.T., Murray, J.A. (2010). Muscosal recovery and mortality in adults with celiac disease after treatment with a gluten-free diet. The American Journal of Gastroenterology, 105(6), 1412-1420.

https://doi.org/10.1038/ajg.2010.10

Sanguinetti, A.M., Secchi, N., Del Caro, A., Fadda, C., Fenu, P.A.M., Catzeddu, P., Piga, A. (2015). Gluten-free fresh filled pasta: The effects of xanthan and guar gum on changes in quality parameters after pasteurisation and during storage. LWT-Food Science and Technology, 64(2), 678-684. https://doi.org/10.1016/j.lwt.2015.06.046

Sapone, A., Bai, J.C., Ciacci, C., Dolinsek, J., Green, P.H.R., Hadjivassiliou, M., Kaukinen, K., Rostami, K., Sanders, D.S., Schumann, M., Ullrich, R., Villalta, D., Volta, U., Catassi, C., Fasano, A. (2012). Spectrum of gluten-related disorders: Consensus on new nomenclature and classification. BMC Medicine, 10, 13. 
https://doi.org/10.1186/1741-7015-10-13

Scherf, K.A., Koehler, P., Wieser, H. (2016). Gluten and wheat sensitivities - An overview. Journal of Cereal Science, 67, 2-11.

https://doi.org/10.1016/j.jcs.2015.07.008

Silvester, J.A., Weiten, D., Graff, L.A., Walker, J.R., Duerksen, D.R. (2016). Is it gluten-free? Relationship between self-reported gluten-free diet adherence and knowledge of gluten content of foods. Nutrition, 32(7-8), 777-783.

https://doi.org/10.1016/j.nut.2016.01.021

Smulders, M.J.M., van de Wiel, C.C.M., van den Broeck, H.C., van der Meer, I.M., Israel-Hoevelaken, T.P.M., Timmer, R.D., van Dinter, B.J., Braun, S., Gilissen, L.J.W.J. (2018). Oats in healthy gluten-free and regular diets: A perspective. Food Research International, 110, 3-10. https://doi.org/10.1016/j.foodres.2017.11.031

Talens, C., Álvarez-Sabatel, S., Rios, Y., Rodríguez, R. (2017). Effect of a new microwave-dried orange fibre ingredient vs. a commercial citrus fibre on texture and sensory properties of gluten-free muffins. Innovative Food Science and Emerging Technologies, 44, 83-88. https://doi.org/10.1016/j.ifset.2017.07.011
Taşbaş, H., Osanmaz, E., Özer, C.O., Kiliç, B. (2016). Quality characteristics and storage stability of gluten-free coated chicken nuggets. Carpathian Journal of Food Science and Technology, 8(4), 91-102.

Unalp-Arida, A., Ruhl, C.E., Choung, R.S., Brantner, T.L., Murray, J.A. (2017). Lower prevalence of celiac disease and gluten-related disorders in persons living in Southern vs Northern latitudes of the United States. Gastroenterology, 152, 1922-1932.

https://doi.org/10.1053/j.gastro.2017.02.012

U.S. Food and Drug Administration. (2018). Questions and answers: gluten-free food labeling final rule, Retrieved from https://www.fda.gov/Food/GuidanceRegulation/GuidanceDocumentsRegulatoryInformation/Allergens/ucm362880.htm (accessed 01.10.2018)

Vici, G., Belli, L., Biondi, M., Polzonetti, V. (2016). Gluten free diet and nutrient deficiencies: A review. Clinical Nutrition, 35(6), 1236-1241.

https://doi.org/10.1016/j.clnu.2016.05.002

Yalçin, E., Çelik, S., Köksel, H. (2008). Chemical and sensory properties of new gluten-free food products: rice and corn tarhana. Food Science and Biotechnology, 17(4), 728733. 